\title{
Rejection of ammonium and nitrate from sodium chloride solutions by nanofiltration: Effect of dominant-salt concentration on the trace-ion rejection
}

Mònica Reigi, ${ }^{1,}$ Edxon Licon¹, Oriol Gibert1,2, Andriy Yaroshchuk1,3 and José Luis Cortina1,2.

${ }^{1}$ Chemical Engineering Dept. UPC-Barcelona TECH, Av. Diagonal 64708028 Barcelona, Spain

${ }^{2}$ CETAQUA Carretera d'Esplugues, 75, 08940 Cornellà de Llobregat, Spain

${ }^{3}$ Catalan Institute for Research and Advanced Studies (ICREA), Barcelona, Spain

*Corresponding author: Tel.:+34 93 4016997; E-mail address: monica.reig@upc.edu

\begin{abstract}
In this work, the rejection of two ions associated with fertilizer pollution of ground water $\left(\mathrm{NH}_{4}^{+}\right.$and $\left.\mathrm{NO}_{3}{ }^{-}\right)$ by a polyamide nanofiltration (NF270) membrane was studied. Sodium chloride was selected as the dominant salt and the effect of its concentration on the $\mathrm{NH}_{4}{ }^{+}$and $\mathrm{NO}_{3}{ }^{-}$rejections was evaluated. Filtration experiments were carried out in a cross-flow setup with a rectangular spacer-filled feed channel. The solution-diffusion-electro-migration-film model (SDEFM), previously developed to model the pressuredriven trans-membrane transfer of electrolyte mixtures consisting of a single dominant salt and (any number of) trace ions, was used to obtain membrane ion permeance from the experimental data. In this way, the membrane permeances with respect to single ions $\left(\mathrm{Na}^{+}, \mathrm{Cl}^{-}, \mathrm{NH}_{4}^{+}, \mathrm{NO}_{3}{ }^{-}\right)$were obtained for various concentrations of both dominant $(0.05$ to $0.3 \mathrm{M} \mathrm{NaCl})$ and trace salts $\left(0.001\right.$ to $\left.0.003 \mathrm{M} \mathrm{NH} \mathrm{Cl}_{4} / \mathrm{NaNO}_{3}\right)$. It was observed that when the dominant salt concentration increased, the rejections of dominant salt and trace ions decreased, whereas the membrane permeances to ions increased. This information can be useful for developing design tools for nanofiltration of mixed electrolyte solutions in water-treatment applications.
\end{abstract}


Keywords: ion rejection, nitrate and ammonium, dominant salt, trace ion, concentration effect, ionic permeance

\section{Introduction}

Coastal zones are typically densely populated areas as they generally present the best conditions for productivity. However, these regions face many hydrological problems like flooding wave surge and drinking water scarcity due to the problem of salt water intrusion. In the case of areas with intensive agriculture the overdosing of mineral and organic fertilizers deteriorates groundwater quality affected potentially by $\mathrm{NaCl}$ via the sea-water intrusion in combination with the incorporation of N-based ions (e.g. ammonium and nitrate). Groundwater treatments often use ion exchange or membrane-based processes (e.g. reverse osmosis, nanofiltration, electrodialysis) to reduce salinity.

Most commercially available nanofiltration (NF) membranes have a thin-film composite structure, consisting of an ultrathin top polyamide active layer $(\sim 50-200 \mathrm{~nm})$, an intermediate polysulfone support $(\sim 50 \mu \mathrm{m})$ and a backing of nonwoven polyester fibers $(\sim 100 \mu \mathrm{m})$. Within the scope of the solutiondiffusion-electromigration model (SDEFM) it is postulated that the ability of ions to diffuse through this active layer eventually controls the ion rejection. This transport may strongly depend on the ion properties (charge and size). Thus, comparing how ions with different properties and at different concentrations interact with the active layers can improve our understanding of the mechanisms controlling ions transport and rejection by $\mathrm{NF}$ membranes. $\mathrm{NaCl}$ rejection by $\mathrm{NF}$ membranes has been widely studied previously [15]. Less effort has been devoted to $\mathrm{NO}_{3}{ }^{-}$and $\mathrm{NH}_{4}{ }^{+}$rejection studies. Su et al. [1] studied the rejection in mixtures of $\mathrm{Na}^{+}, \mathrm{Ca}^{2+}, \mathrm{Cl}^{-}$and $\mathrm{NO}_{3}{ }^{-}$for a concentration range 0.01 to $0.04 \mathrm{M}$ (at $\mathrm{pH}$ 6.5). Paugam et al. [6] conducted experiments with $\mathrm{NaNO}_{3}$ and $\mathrm{NH}_{4} \mathrm{NO}_{3}$, using a spiral-wound $\mathrm{NF}$ membrane module. In the studied concentration range (from $0.8 \cdot 10^{-3}$ to $3 \cdot 10^{-3} \mathrm{M}$ at $\mathrm{pH} 5.8$ ) the removal of $\mathrm{NO}_{3}{ }^{-}$decreased when the feed salt concentration increased and this effect was attributed to the increased screening of membrane surface charge. 
Despite the wide use of NF worldwide, even at industrial scale, there are still difficulties in establishing its predictive model. This is due to the complexity of mechanisms of solvent and solute transport through NF membranes. As reviewed recently by Wang et al. various NF models still coexist [7]. Basically, some models [8-11] use a nanopore assumption for the membrane structure to describe the behavior of ions inside the membrane, while others [12-15] postulate that there are no permanent nanopores inside the membrane. In any case, the model capability to predict the ions rejections from complex mixtures has been shown to be rather limited. At the same time, the use of reasonably justified simplified models can be of significant practical value. Thus for instance, the SDEFM can describe the transport of electrolyte mixtures through NF membranes $[16,17]$. This model assumes that there are no permanent pores in the membrane active layer but there is a free volume instead. SDEFM describes the trans-membrane ion transport taking into account diffusion and electro-migration within the active layer as well as external concentration polarization [16]. SDEFM can describe and fit the experimental rejection curves of both dominant salt and trace ions. From this fitting, the membrane permeances towards each ion can be estimated.

Membrane permeances with respect to cations and anions of the dominant salt are probably different; this means that one of the ions is transported through the membrane easier than the other. The differences between the membrane permeances with respect to cations and anions of dominant salt always lead to electric fields that arise to keep to ion transfer stoichiometric (and the electric current zero). These electric fields influence the transport of trace ions and negative rejections may occur [18].

Generally, ionic permeances are functions of feed composition and may also change across the membrane due to the ion rejection. To take this into account, Bason et al. [15] postulated a procedure to model rejection data by using two general phenomenological coefficients: the concentration-dependent salt permeance and the Péclet coefficient. Recently, taking as base that constant permeances can be used as first approximation especially in mixtures where anything more elaborated would be hopelessly complex, Fridman-Bishop [19] analyzed permeance vales accuracy to model seawater rejection and the potential uncertainties of parameter estimation and the importance of permeance to ions compositional dependence.

The model used in this work is an extension of the classical solution-diffusion model, which includes electrolyte mixtures. The majority of reported studies in which ion rejection in electrolyte mixtures were 
studied used numerical approaches and no analytical solutions were obtained. In a previous publication, Yaroshchuk et al. [16] studied the case of a dominant salt and trace ions by means of the model and an analytical solution was obtained. The analytical algebraic solution of transport equations enables rapid exploration of trends in the behavior of membrane systems [20]. In the SDEFM rapid calculations of ion rejections at different transmembrane fluxes through a NF membrane are possible by only adjusting the single-ion permeances as parameters of differential equations. Then, it can be said that the SDEFM is a good advanced engineering model, because it employs only a limited number of adjustable parameters obtainable from a well-defined set of experiments and at the same time it takes into account the principal physicochemical phenomena.

In this study, the rejections of sodium, chloride, nitrate and ammonium ions by a commercial NF membrane were studied experimentally. Solutions of $\mathrm{NaCl}$ (as dominant salt) of various concentrations were mixed with $\mathrm{NH}_{4} \mathrm{Cl}$ and $\mathrm{NaNO}_{3}$ as traces in order to study the effect of dominant salt concentration on the trace ions rejection $\left(\mathrm{NH}_{4}{ }^{+}\right.$and $\left.\mathrm{NO}_{3}{ }^{-}\right)$. Besides, the rejection data were modelled by means of the SDEFM to describe the ion rejection behavior as a function of trans-membrane flux. As a result, the membrane permeances to each ion $\left(\mathrm{Na}^{+}, \mathrm{Cl}^{-}, \mathrm{NH}_{4}{ }^{+}\right.$and $\left.\mathrm{NO}_{3}{ }^{-}\right)$were also estimated. The dependences of salt and ion permeances on the feed solution composition were analyzed.

Trace ammonium and nitrate rejections from dominant sodium chloride solutions have been modeled by the SDEFM for the first time. These ions usually appear as trace ions in salty solutions and are of interest because of environmental concerns. In this work, sodium chloride was used as the main salt and its concentration effect on the rejection of trace ions has been studied and modelled obtaining good fits for all of them: dominant salt as well as trace ions. The experimental data were successfully modelled and ion permeances were determined as functions of the dominant-salt concentration for the first time. 


\section{Materials and methods}

\subsection{Experimental set-up description and operation}

A flat-sheet cross-flow test cell with a NF-270 membrane, supplied by Dow Chemical, was used to carry out the experimental part of this work. The membrane was a polyamide thin-film composite with $0.014 \mathrm{~m}^{2}$ of effective area.

The experimental setup was described previously $[21,22]$. The feed solution was placed in a refrigerated tank and pumped into the membrane test cell. After the NF process, both permeate and concentrate streams were recirculated to the feed tank in order to keep constant the feed solution composition. The concentrate stream passed through a cartridge filter before entering the feed tank again to keep this stream free of particulate matter. The permeate stream was monitored in terms of $\mathrm{pH}$, conductivity and temperature during the experimentation. Permeate samples were periodically collected by using a three way valve, and the ion analysis was done by chromatography on the completion of experiments. Inlet and outlet pressure of the feed circuit of membrane test cell as well as the concentrate flow rate were also monitored throughout the experiments. From the inlet and outlet pressure values it was possible to calculate the average transmembrane pressure (TMP) inside the test cell.

Before starting each experiment, de-ionized water was pumped into the membrane test cell for one hour and a half at the maximum TMP and cross-flow velocity. Immediately thereafter, the same procedure was repeated with the synthetic salt solution to minimize irreversible membrane compaction in the course of the ion-rejection measurements. Then, the experiment was started. An initial sample of the feed solution was taken. During the experiment the temperature and the flow rate were kept constant, while the TMP was increased in steps of 2 bars from 1 to 20 bar. At each TMP, several permeate samples were collected after the permeate conductivity reached a constant value. When increasing the TMP, the trans-membrane flux also increased, while the permeate conductivity diminished. Before turning off the pump, a feed sample was collected again in order to corroborate that its composition was kept constant over the experiments. 


\subsection{Experimental protocols}

The experiments were designed to study 1) the dominant-salt concentration effect on the trace-ion rejection and 2) the trace-ion concentration effect on its rejection at a given dominant-salt concentration. With the purpose of mimicking an $\mathrm{NH}_{4}{ }^{+}$and $\mathrm{NO}_{3}{ }^{-}$contaminated groundwater suffering seawater intrusion, feed water consisted of deionized water spiked with $\mathrm{NaCl}$ as dominant salt and $\mathrm{NH}_{4} \mathrm{Cl}$ and $\mathrm{NaNO}_{3}$ as trace salts. The focus on $\mathrm{NH}_{4}^{+}$and $\mathrm{NO}_{3}^{-}$is justified by their environmental relevance (both are common surface and groundwater contaminants due to waste water discharges or drainage from agriculture and farming activities).

In the first set of experiments, $\mathrm{NaCl}$ concentration ranged from 0.05 to $0.3 \mathrm{M}$, while the concentrations of $\mathrm{NH}_{4} \mathrm{Cl}$ and $\mathrm{NaNO}_{3}$ were kept constant at $0.002 \mathrm{M}$. For the second set of experiments, a constant $\mathrm{NaCl}$ concentration of $0.2 \mathrm{M}$ was used while $\mathrm{NH}_{4} \mathrm{Cl}$ and $\mathrm{NaNO}_{3}$ concentrations were varied from 0.001 to $0.003 \mathrm{M}$. Table 1 shows the concentration values of the dominant and trace salts in each experiment.

Table 1. Concentration experimental design

\begin{tabular}{|c|c|c|c|c|}
\hline \multirow{3}{*}{ Experiment } & \multicolumn{3}{|c|}{ Concentration (mol/L) } & \\
\hline & Dominant salt & \multicolumn{2}{|c|}{ Trace salt } & \\
\hline & $\mathrm{NaCl}$ & $\mathrm{NH}_{4} \mathrm{Cl}$ & $\mathrm{NaNO}_{3}$ & $\mathrm{pH}$ \\
\hline 1 & 0.05 & 0.002 & 0.002 & 5.8 \\
\hline 2 & 0.1 & 0.002 & 0.002 & 5.8 \\
\hline 3 & 0.2 & 0.002 & 0.002 & 5.7 \\
\hline 4 & 0.3 & 0.002 & 0.002 & 5.6 \\
\hline
\end{tabular}

\subsection{Analytical methodologies and chemical analysis}

The conductivity, temperature and $\mathrm{pH}$ were routinely measured for the permeate stream with a multimeter (CRISON, MM41) to give a rough estimate of ion rejection. Once an experiment was finished, each permeate and feed sample was analyzed by ionic chromatography (Dionex ICS-1000) in order to accurately 
determine the concentrations (and hence the rejection) of each ion. The cation and anion analyses were performed by using two different analytical columns, IONPAC ${ }^{\circledR}$ CS16 and IONPAC ${ }^{\circledR}$ AS23 (Dionex), respectively.

\subsection{Solution-diffusion-electromigration-film model}

The SDEFM uses the membrane permeances to the ions of the dominant and trace salts as well as the thickness of the unstirred layer as parameters to describe the rejections of all the species as a function of the trans-membrane flow. Inversely, by using experimentally observable rejections, the model can be used to estimate the ionic permeances and the stagnant-layer thickness from experimental data as described in [21]. Briefly, the procedure was as follows. First, the observable rejection of dominant salt was fitted by using $\mathrm{Eq}$ (1) from Table 2. From this fitting, the diffusion permeance of the unstirred layer was estimated. From it, the unstirred-layer thickness was estimated by using the bulk diffusion coefficient of each salt known from the literature. The estimated unstirred-layer thickness (along with the bulk diffusion coefficients of trace ions) was then used to account for the concentration adjacent to the membrane of trace ions by using $\mathrm{Eq}(3)$ and calculate their intrinsic rejections. Finally, $\mathrm{Eq}(4)$ was used to determine the intrinsic rejection of trace ions to adjust parameters $b$ and $K$. The latter (along with the membrane permeance to the dominant salt known from the dominant-salt fitting) was used to obtain the ionic permeances of all dominant and trace ions. For further details, the reader is referred to [16,21]. 
Table 2. Summary of the equations of the model

\section{Dominant salt}

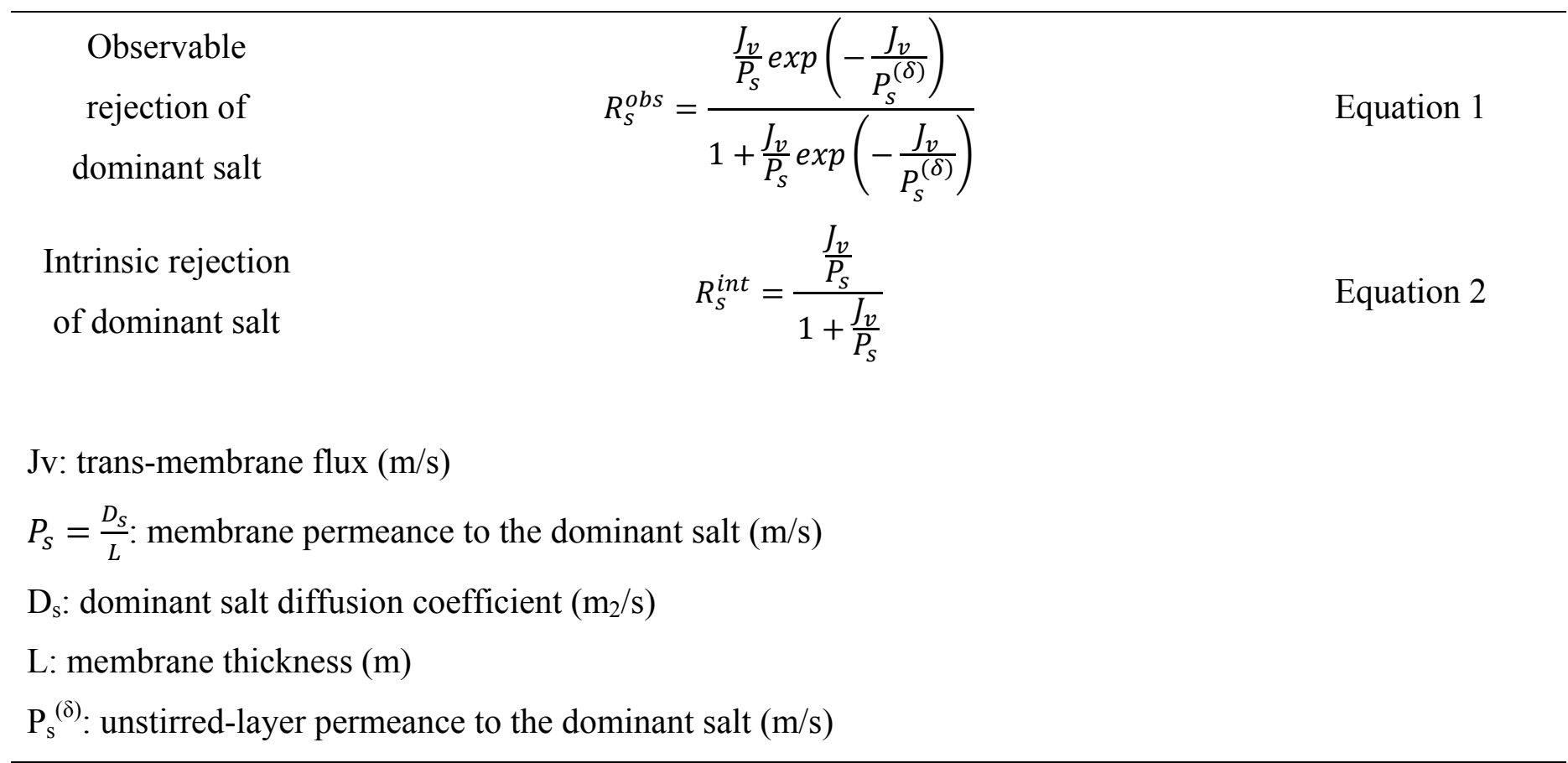

\section{Trace ions}

$$
\begin{aligned}
& \frac{c_{t}^{(m)}}{c_{t}^{\prime}}=\exp \left(P e_{t}\right) {\left[1+R_{s}^{o b s}\left(\exp \left(P e_{s}\right)-1\right)\right]^{b^{(\delta)}} } \\
& \cdot\left\{1-\left(1-R_{t}^{o b s}\right) \int_{\exp \left(-P e_{t}\right)}^{1} \frac{d y}{\left[1+R_{s}^{o b s}\left(y^{-\alpha}-1\right)\right]^{b^{(\delta)}}}\right\}
\end{aligned}
$$

Equation 3

$\mathrm{c}_{\mathrm{t}}^{(\mathrm{m})}$ : concentration of the trace ion at the membrane surface $\left(\mathrm{mol} / \mathrm{m}^{3}\right)$

$c_{t}$ : concentration of the trace ion in the feed solution $\left(\mathrm{mol} / \mathrm{m}^{3}\right)$

$P e_{t}=\frac{J_{v} \cdot \delta}{D_{t}^{\delta}}:$ Péclet number of trace ion

$P e_{S}=\frac{J_{v} \cdot \delta}{D_{s}^{(\delta)}}:$ Péclet number of dominant salt

$\delta=\frac{D_{s}^{(\delta)}}{P_{S}^{(\delta)}}$ : concentration-polarization layer thickness $(\mathrm{m})$

$D_{t}^{(\delta)}$ : diffusion coefficient of trace ion in concentration-polarization layer $\left(\mathrm{m}^{2} / \mathrm{s}\right)$

$D_{s}^{(\delta)}=\frac{\left(\mathrm{Z}_{+}-\mathrm{Z}_{-}\right) \mathrm{D}_{+}^{(\delta)} \mathrm{D}_{-}^{(\delta)}}{\mathrm{Z}_{+} \mathrm{D}_{+}^{(\delta)}-\mathrm{Z}_{-} \mathrm{D}_{-}^{(\delta)}}$ : diffusion coefficient of dominant salt in concentration-polarization layer $\left(\mathrm{m}^{2} / \mathrm{s}\right)$

$\mathrm{D}_{ \pm}{ }^{(\delta)}$ : diffusion coefficients of ions of dominant salt in the concentration-polarization layer $\left(\mathrm{m}^{2} / \mathrm{s}\right)$

$\mathrm{Z}_{ \pm}$: charges of ions of dominant salt

$b^{\delta} \equiv \frac{Z_{t} \cdot\left(D_{+}^{(\delta)}-D_{-}^{(\delta)}\right)}{Z_{+} D_{+}^{(\delta)}-Z_{-} D_{-}^{(\delta)}}$ 
$\alpha=\frac{D_{t}^{(\delta)}}{D_{s}^{(\delta)}}$

Reciprocal intrinsic

transmission of a

$$
f_{t}=\left(f_{s}\right)^{b}+K\left(\frac{f_{s}-\left(f_{s}\right)^{b}}{1-b}\right)
$$

trace ion

$f_{s}=\left(\frac{1}{1-R_{S}{ }^{i n t}}\right):$ reciprocal intrinsic transmission of the dominant salt

$f_{t}=\left(\frac{1}{1-R_{t}{ }^{i n t}}\right)$

$\mathrm{R}_{\mathrm{t}}{ }^{\text {int }}$ : intrinsic rejection of the trace ion

$b \equiv \frac{Z_{t}\left(P_{+}-P_{-}\right)}{Z_{+} P_{+}-Z_{-} P_{-}}$

$Z_{t}$ : charge of the trace ion

\section{Membrane permeance}

\begin{tabular}{lll}
\hline Permeance to & $P_{ \pm}=\frac{P_{s}}{1-\left(\frac{z_{ \pm}}{z_{t}}\right) b}$ & Equation 5 \\
single ions of the & & \\
dominant salt & & Equation 6 \\
Membrane & $P_{t}=\frac{P_{s}}{K}$ & \\
permeance to trace & & \\
ions & & \\
\hline
\end{tabular}

\subsection{NF270 properties}

Previously, salt permeances have been correlated to the total dominant salt content in the membrane and to changes in the membrane effective fixed charge. The latter could be related to specific ion adsorption and competitive binding of counterions to the fixed charge sites that diminishes effective fixed charge via ion association [19]. New membrane characterization techniques [23-25] have shown that aromatic polyamide active layers produced by interfacial polymerization, as it is the case of NF270, were characterized by a concentration of ionizable functional groups related to the degree of polymer cross-linking. Each carboxylic $\left(\mathrm{RCOOH} / \mathrm{R}-\mathrm{COO}^{-}\right)$and amine $\left(\mathrm{R}-\mathrm{NH}_{3}{ }^{+} / \mathrm{R}^{-} \mathrm{NH}_{2}\right)$ groups correspond to an amide link not formed during the polyamide polymerization reaction. Ionizable functional groups affect water and solute permeation not only because they produce $\mathrm{pH}$-dependent charges in the active layer [24-26], but also because they affect the active layer structure [24,25]. For the case of NF270, although no data on the determination of the acid-base 
properties of the carboxylic groups have been published, most of the studies indicate that at neutral $\mathrm{pH}$ values 6-7, carboxylic groups is deprotonated ( $\left.\mathrm{R}-\mathrm{COO}^{-}\right)$. Then, in the present study where experiments were performed at $\mathrm{pH}$ around 6.6, the carboxylic groups were assumed to be deprotonated so the permeance to $\mathrm{Na}^{+}$was expected to be significantly higher than to $\mathrm{Cl}^{-}$. Nevertheless, it must be stressed that it is a priori uncertain which ion, $\mathrm{Na}^{+}$or $\mathrm{Cl}^{-}$, would be the faster.

\subsection{Concentration dependence of salt permeance}

Although the SDEFM considers constant the ionic permeances across the membrane, nothing prevents us from considering them functions of feed composition. Even though this is a kind of contradiction since the dependence on the feed composition implies some variation across the membrane, it should be mentioned that the Spiegler-Kedem Model (SKM) [27] often describes rejection data quite well although it also disregards the variation of transport coefficient across the membrane. At the same time, the SKM has been successfully used to parameterize dependences of membrane rejection on the feed composition.

\section{Results and discussion}

\subsection{Dominant salt concentration effect on the trace ions removal}

A typical plot of ion rejection vs. trans-membrane flux is shown in Figure 1. This corresponds to $0.1 \mathrm{M} \mathrm{NaCl}$ as dominant salt and $0.002 \mathrm{M} \mathrm{NH} \mathrm{Nl}_{4}$ and $0.002 \mathrm{M} \mathrm{NaNO}_{3}$ as trace salts. The symbols represent the experimental points and the lines were calculated by using the SDEFM equations (Table 2). From the fitting process, as described in section 2.4, membrane permeances to dominant and trace ions were determined. 


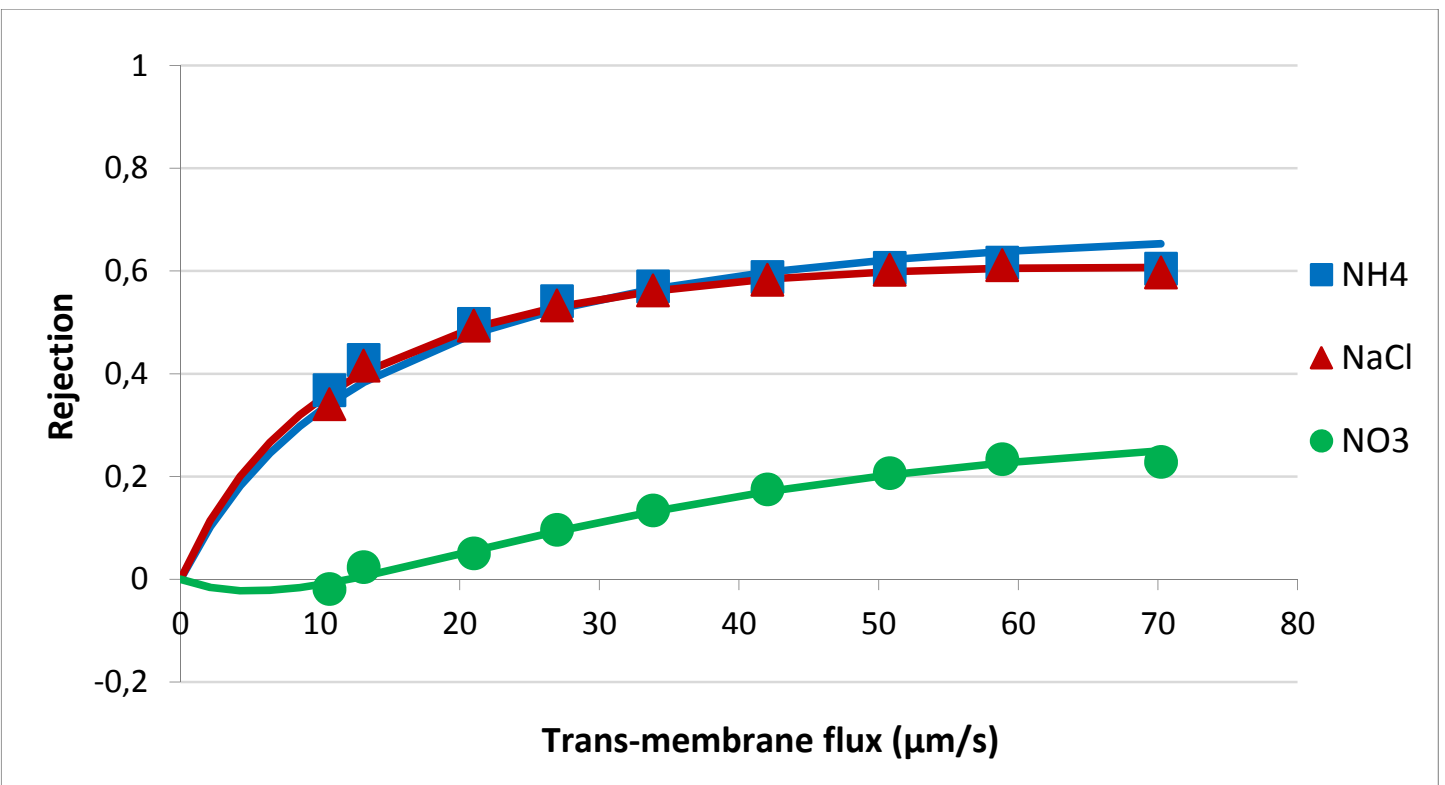

Figure 1. Experimental $\mathrm{NaCl}, \mathrm{NH}_{4}^{+}$and $\mathrm{NO}_{3}^{-}$rejections vs. trans-membrane volume flux; feed concentrations: $0.1 \mathrm{M} \mathrm{NaCl}, 0.002 \mathrm{M} \mathrm{NH} \mathrm{Nl}_{4} \mathrm{Cl}$ and $0.002 \mathrm{M} \mathrm{NaNO}_{3}$. Solid lines represent the modelling by means of SDEFM.

As shown in Figure 1 the rejection of $\mathrm{NaCl}$ and $\mathrm{NH}_{4}{ }^{+}$increased with the trans-membrane flux in a monotone way as reported previously on numerous occasions [21,22]. However, $\mathrm{NO}_{3}{ }^{-}$displayed a different behavior, namely slightly negative rejections at small trans-membrane fluxes. Negative rejections can occur due to the difference between the membrane permeances with respect to the dominant cations and anions. In this study, the membrane permeance to $\mathrm{Na}^{+}$ion was higher than to $\mathrm{Cl}^{-}$indicating that $\mathrm{Na}^{+}$passed more easily through the membrane, as expected taking into account the acid-base membrane properties (see section 2.5). As a consequence, a trans-membrane electric field arose to make the transfer of dominant cations and anions stoichiometric (and electric current zero). This field enhanced the transport of monovalent negative trace ions, and negative rejections might occur, as in the case of $\mathrm{NO}_{3}{ }^{-}$at low TMP values (as it will be explained in more detailed in this section). At higher TMPs $\mathrm{NO}_{3}{ }^{-}$rejection increased to positive values, although the values were quite far from those obtained for $\mathrm{NaCl}$ or $\mathrm{NH}_{4}{ }^{+}$. Finally, Figure 1 shows that the model was able to satisfactorily fit the experimental data for the dominant salt and trace ions.

A crucial feature of the SDEFM is the coupling between ion fluxes through the electric field, which makes the ion transport distinctly different from that of uncharged species. The source of the potential gradient 
across the membrane is ion permeance differences. In the case of higher cation permeance, the potential difference is expected to enhance the anion passage and reduce the cations passage, and vice versa. At lower dominant salt concentration even though $\mathrm{NH}_{4}{ }^{+}$and $\mathrm{NO}_{3}{ }^{-}$may not behave as ideal traces, their effect on the potential gradient may initially be moderate. However, at high dominant salt concentration trace ions should have an increasing effect on the potential difference across the membrane decreasing its rejection.

Figure 2 shows the dominant salt $(\mathrm{NaCl})$ and trace ions $\left(\mathrm{NH}_{4}{ }^{+}\right.$and $\left.\mathrm{NO}_{3}{ }^{-}\right)$rejections at various $\mathrm{NaCl}$ feed concentrations $(0.05,0.1,0.2$ and $0.3 \mathrm{M})$.

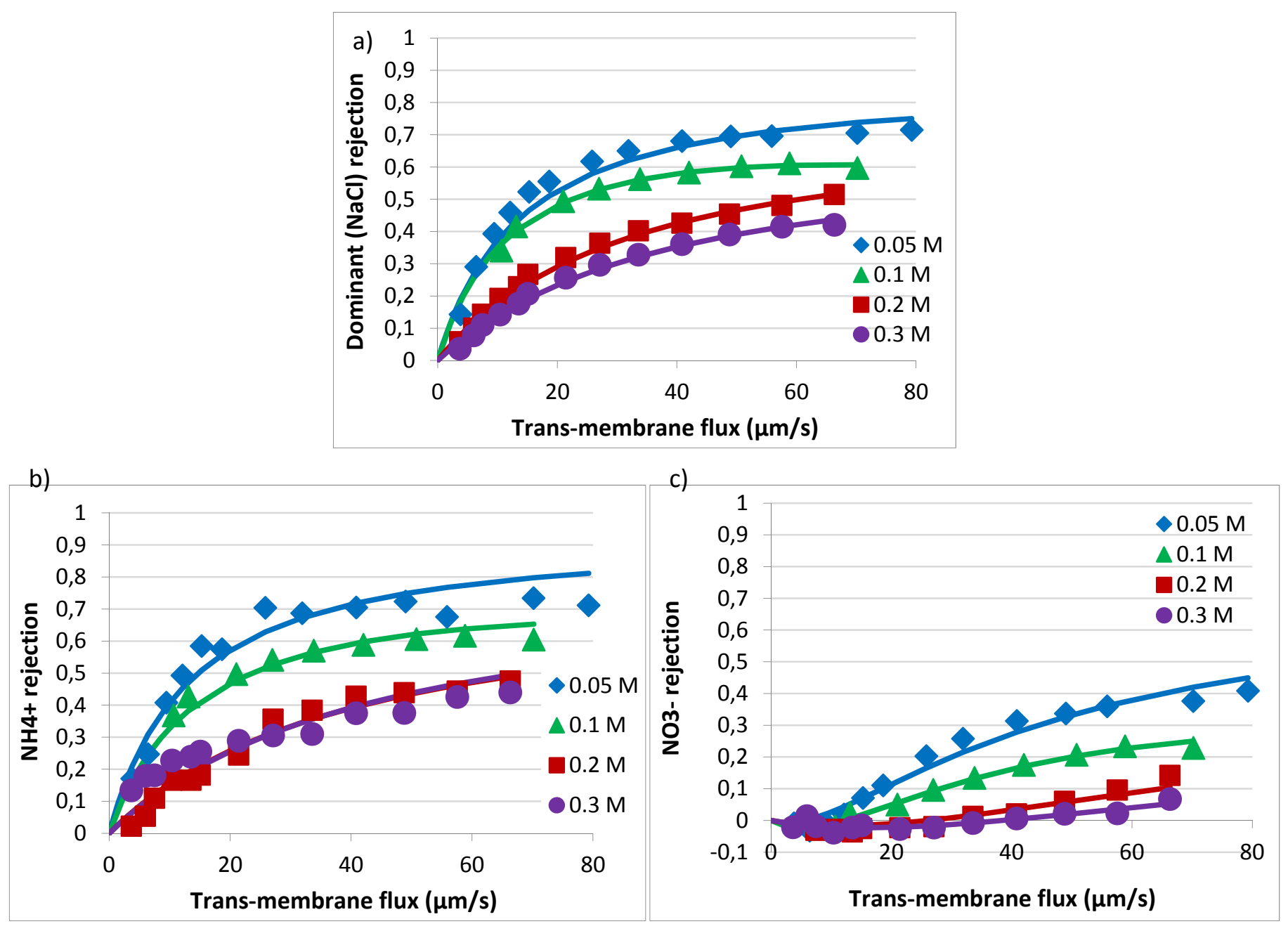

Figure 2. Experimental a) $\mathrm{NaCl}$, b) $\mathrm{NH}_{4}{ }^{+}$and b) $\mathrm{NO}_{3}{ }^{-}$rejections vs. trans-membrane flux at various dominant salt feed concentration of $0.05,0.1,0.2$ and $0.3 \mathrm{M} \mathrm{NaCl}$. Solid lines represent the modelling by means of SDEFM. 
Figure 2a shows that an increase in $\mathrm{NaCl}$ concentration led to a decrease of its rejection: using $0.05 \mathrm{M} \mathrm{NaCl}$ a maximum rejection of around $70 \%$ were obtained, while working with $0.3 \mathrm{M} \mathrm{NaCl}$ approximately $40 \%$ were reached. This effect was more pronounced in the change from $0.05 \mathrm{M}$ to $0.1 \mathrm{M}$ and $0.1 \mathrm{M}$ to $0.2 \mathrm{M}$, being less abrupt when changing from $0.2 \mathrm{M}$ to $0.3 \mathrm{M}$.

A number of studies using NF 270 [28] or similar aromatic polyamide membranes $[4,15]$ or even using silica $\mathrm{NF}$ modified with iron [29] described a similar effect of feed concentration on $\mathrm{NaCl}$ rejections. In all the cases an increase in the $\mathrm{NaCl}$ concentration led to a decrease in its rejection. For instance, a $20 \%$ of $\mathrm{NaCl}$ rejection was obtained with a $0.05 \mathrm{M} \mathrm{NaCl}$ solutions, whereas rejections of $80 \%$ were achieved with $\mathrm{NaCl}$ concentration lower than $0.001 \mathrm{M}$ [29]. A summary of the measured $\mathrm{Ps}(\mathrm{NaCl})$ values for the different ranges evaluated are summarized in Table 3 and plotted in Figure 3.

The $\mathrm{NH}_{4}{ }^{+}$rejection (Figure $2 \mathrm{~b}$ ) presented a similar behavior as the dominant salt. Its rejection decreased with increasing the dominant salt concentration, with a maximum rejection of $76 \%$ when using $0.05 \mathrm{M} \mathrm{NaCl}$ and less than $50 \%$ when working with $0.3 \mathrm{M} \mathrm{NaCl}$. Besides, the $\mathrm{NH}_{4}{ }^{+}$rejection at 0.2 or $0.3 \mathrm{M}$ of $\mathrm{NaCl}$ was almost the same, corroborating the hypothesis of the existence of a threshold in the $\mathrm{NaCl}$ concentration beyond which the effect of the higher concentration was not noticeable. Figure $2 \mathrm{c}$ shows that $\mathrm{NO}_{3}{ }^{-}$rejections were lower than that of $\mathrm{NaCl}$ and $\mathrm{NH}_{4}{ }^{+}$for all $\mathrm{NaCl}$ concentrations (maximum rejection values for $\mathrm{NO}_{3}{ }^{-}$ between $6 \%$ and 41\%). Similarly to what was observed with $\mathrm{NH}_{4}{ }^{+}, \mathrm{NO}_{3}{ }^{-}$rejection also decreased with increasing $\mathrm{NaCl}$ concentration. Su et al. [1] studied ion rejection in mixtures of $\mathrm{Na}^{+}, \mathrm{Cl}^{-}, \mathrm{NO}_{3}{ }^{-}$and $\mathrm{Ca}^{2+}$ for a concentration range from 0.01 to $0.04 \mathrm{M}$, at $\mathrm{pH}$ between 6.4-6.6. According to the authors, the repulsion forces of the negative charges of the membrane to the cations with lower charge density were weaker, and therefore the membrane showed a higher permeance and lower rejection towards $\mathrm{Na}^{+}$. In the case of $\mathrm{Cl}^{-}$and $\mathrm{NO}_{3}{ }^{-}$, their observed rejections were almost constant and hardly changed with the equivalent fractions of $\mathrm{Cl}^{-}$ and $\mathrm{NO}_{3}{ }^{-}$in binary electrolyte solutions. 


\subsection{Dependence of the membrane permeance towards $\mathrm{NaCl}$ upon $\mathrm{NaCl}$ concentration}

The difference in the rejections of dominant and trace ions lies on the membrane permeance towards them. The increase of $\mathrm{NaCl}$ permeances with the increase of dominant salt concentration is shown in Table 3 .

Table 3. $\mathrm{NaCl}$ permeance values obtained by SDEFM at different $\mathrm{NaCl}$ concentrations.

\begin{tabular}{|c|c|c|}
\hline $\begin{array}{c}\mathbf{N a C l} \\
\text { concentration } \\
(\mathbf{M})\end{array}$ & $\begin{array}{c}\mathbf{N a C l} \\
\text { permeance } \\
(\mu \mathrm{m} / \mathbf{s})\end{array}$ & $\begin{array}{c}\text { Unstirred-layer } \\
\text { permeance to the } \\
\text { dominant salt }(\boldsymbol{\mu m} / \mathbf{s})\end{array}$ \\
\hline $\mathbf{C}_{\mathrm{NaCl}}$ & $\mathbf{P}_{\mathbf{s}}$ & $\mathbf{P}_{\mathbf{s}}{ }^{\mathbf{N}}$ \\
\hline 0.05 & 15.9 & $156.5 \pm 0.07$ \\
\hline 0.1 & 22.0 & $120.2 \pm 0.01$ \\
\hline 0.2 & 43.6 & $185.2 \pm 0.03$ \\
\hline 0.3 & 58.3 & $172.7 \pm 0.02$ \\
\hline
\end{tabular}

As can be seen from Table 3, as $\mathrm{NaCl}$ concentration increased, $\mathrm{NaCl}$ permeance increased too. Regarding the unstirred-layer permeance value, it can be seen that there was not a strong dependence of unstirred-layer permeance on the concentration. For the $\mathrm{P}_{\mathrm{s}}^{\delta}$ value at $0.1 \mathrm{M}$, an average including result of this work and previous studies at the same $\mathrm{NaCl}$ concentration, experimental conditions and for the same membrane has been considered [21].

Bason et. [15] and Yaroshchuk [30,31] proposed a phenomenological approach to fill the large gap between the experimental data and the physical modelling for the single salt case, using concentration-dependent coefficients in a Spiegler-Kedem-like model: the salt permeance Ps, and the reflection coefficient $\sigma_{\mathrm{s}}$. Bason et al. [15,32] suggested that the dependence of effective diffusion coefficient of single (1:1) salts in the barrier layers of NF membranes on the virtual salt concentration can be approximated by the functional form described by $\operatorname{Eq}(7)$ :

$$
P_{s}=a_{1} C_{s}^{a 2}+a_{3}
$$

Equation 7

where $\mathrm{a}_{1}, \mathrm{a}_{2}$, and $\mathrm{a}_{3}$ are fitting constants. 
While this functional form was used for the description of concentration dependence across the membrane, $\mathrm{Eq}(7)$ was used in this work to approximate the dependences of the dominant salt feed concentration on the salt permeance. Then, salt permeance were calculated as a function of salt concentration as $\mathrm{P}_{\mathrm{s}}(\mu \mathrm{m} / \mathrm{s})=$ $168.2 \cdot \mathrm{C}_{\mathrm{NaCl}}^{0.9}+5.0$ (Figure 3).

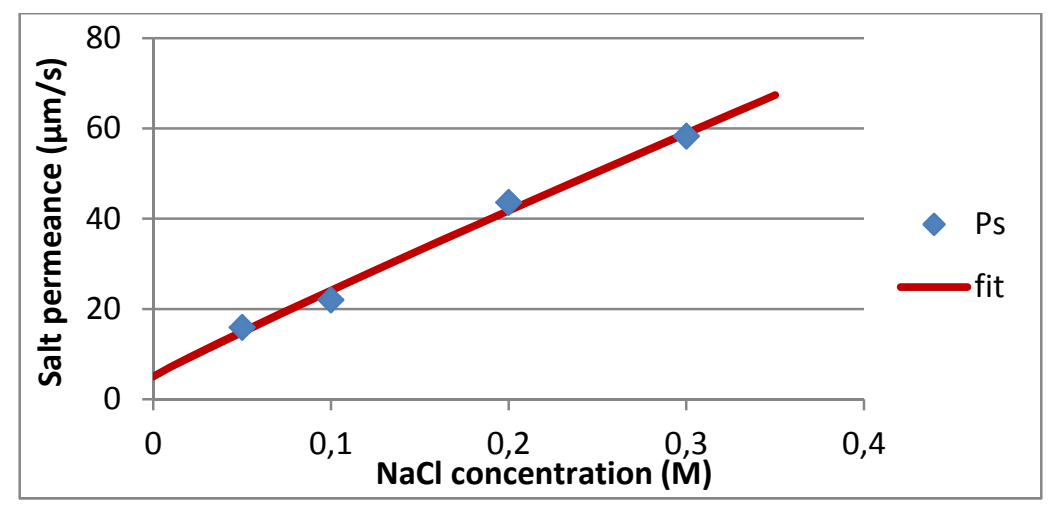

Figure 3. Variation of $\mathrm{P}_{\mathrm{NaCl}}$ values as function of the total initial $\mathrm{NaCl}$ concentration. Solid line is the prediction by $\operatorname{Eq}(7)$ and taking $\mathrm{a}_{1}=168.2, \mathrm{a}_{2}=0.9$ and $\mathrm{a}_{3}=5.0$.

The predicted values (as trend line) are also shown in Figure 3. As proposed by Bason et al. [15], the addition of a finite free term $\mathrm{a}_{3}\left(\mathrm{a}_{3}=5.0\right)$ is suitable for addressing the permeance trend in the low concentration range evaluated. Table 4 lists published results on $\mathrm{Ps}(\mathrm{NaCl})$ with polyamide nanofiltration membranes NF270 [28] and NF200 [15]. As it can be seen, a similar trend on salt permeance increases was reported and ranges of values are quite comparable.

Table 4. Published data on salt permeance as function of salt concentration

\begin{tabular}{|c|c|c|c|c|c|}
\hline \multicolumn{2}{|c|}{ This work } & \multicolumn{2}{c|}{ Bason et al., 2010 [15] } & \multicolumn{2}{c|}{ Hilal et al., 2005 [28] } \\
\hline $\mathrm{C}_{\mathrm{NaCl}}(\mathrm{M})$ & $\mathrm{P}_{\mathrm{s}}$ (NaCl) & $\mathrm{C}_{\mathrm{NaCl}}(\mathrm{M})$ & $\begin{array}{c}\mathrm{P}_{\mathrm{s}}(\mathrm{NaCl}) \\
(\mu \mathrm{m} / \mathrm{s})\end{array}$ & $\mathrm{C}_{\mathrm{NaCl}}(\mathrm{M})$ & \\
& $(\mu \mathrm{m} / \mathrm{s})$ & & 1.5 & 0.09 & 13.9 \\
\hline 0.05 & 15.9 & 0.001 & 2.7 & 0.17 & 18.5 \\
\hline 0.1 & 22.0 & 0.01 & 11.1 & 0.26 & 29.9 \\
\hline 0.2 & 44.6 & 0.1 & 32.5 & 0.34 & 37.8 \\
\hline 0.3 & 58.3 & 0.4 & & 0.43 & 43.3 \\
\hline
\end{tabular}


Values of Ps for each set of data of Bason et al. and Hilal et al. were adjusted by means of Eq(7) and the predicted values are also plotted in Figure 4. Values of the present study are also plotted for comparison and the values of fitting parameters are collected in Table 5.

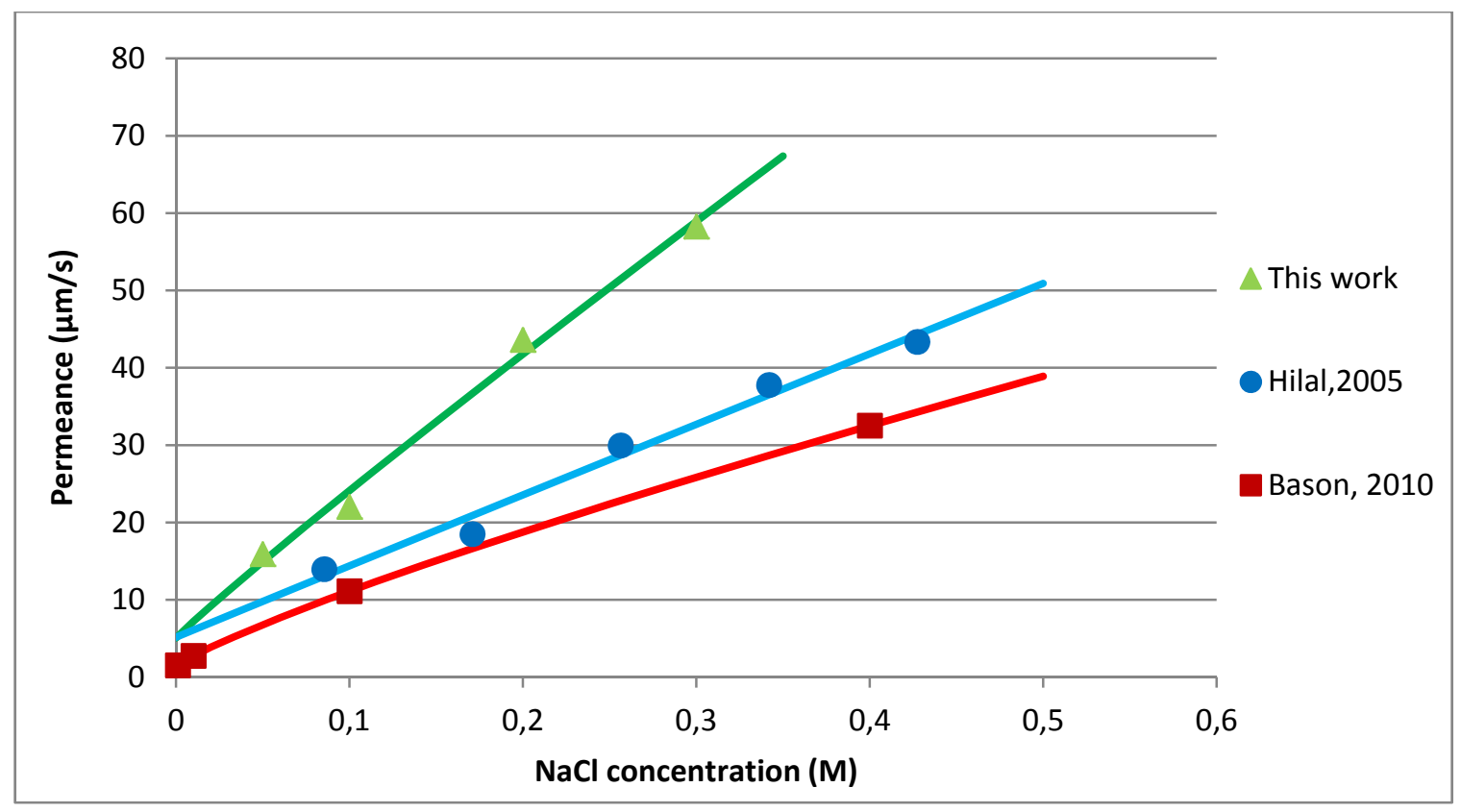

Figure 4. Salt permeance values as function of the feed $\mathrm{NaCl}$ concentration reported by different studies

Table 5. Fitting values for this work and other publications

\begin{tabular}{|c|c|c|c|c|}
\hline Reference & Membrane & a1 & a2 & a3 \\
\hline This work & NF270 & 168.2 & 0.9 & 5.0 \\
\hline Hilal et al., 2005 [28] & NF270 & 91.1 & 1.0 & 5.2 \\
\hline Bason et al., 2010 [15] & NF200 & 67.1 & 0.8 & 1.3 \\
\hline
\end{tabular}

The use of $\mathrm{Eq}(7)$ provided a good fit of the concentration dependence of Ps for the three sets of data. Thus, the concentration dependence on the Ps shown in Figure 4 could be reproducibly obtained by using data from various sources. Accordingly, this dependence may be viewed as an experimental result previously reported by other authors. Then, as such, it could be confronted with various potential rejection mechanisms. 
However, at higher concentrations the permeances measured in this work increased with a slope higher than that obtained by Hilal et al.[28] with the NF270 membrane and by Bason et al. [15] with the NF200 membrane. In the latter case the differences may be related to the different membrane properties (e.g. NF 200 has a medium salt passage, while NF270 has a high salt passage as reported by Dow Chemical).

\subsection{Dependence of membrane permeances towards ions upon dominant salt concentration}

By using the SDEFM it was also possible to "extract" from experimental data the dependence of the permeance on the trace concentration. The membrane permeances towards $\mathrm{NH}_{4}{ }^{+}, \mathrm{Na}^{+}, \mathrm{NO}_{3}{ }^{-}$were similar and higher $(30-180 \mu \mathrm{m} / \mathrm{s})$ than towards $\mathrm{Cl}^{-}(10-35 \mu \mathrm{m} / \mathrm{s})$. This showed that, on the basis only of the ion properties, $\mathrm{NH}_{4}{ }^{+}$and $\mathrm{Na}^{+}$were more prone to pass the $\mathrm{NF}$ membrane followed by $\mathrm{NO}_{3}{ }^{-}$(negative rejections) and $\mathrm{Cl}^{-}$. Regarding the dominant salt $(\mathrm{NaCl})$, it can be said that the results were consistent. NF270 is negatively charged at the working $\mathrm{pH}$ of $6.6 \pm 0.3$; therefore, membrane permeance to $\mathrm{Na}^{+}$was expected to be significantly higher than to $\mathrm{Cl}^{-}$.

It can be seen in Figure 5 that the membrane permeance with respect to a given ion $\left(\mathrm{Na}^{+}, \mathrm{Cl}^{-}, \mathrm{NH}_{4}{ }^{+}, \mathrm{NO}_{3}{ }^{-}\right)$ rose as the $\mathrm{NaCl}$ concentration increased. Only few works has been found related to the dependence of concentration on ion permeances. Fridman-Bishop et al. [19] suggested that an explanation of this dependence could rely on changes in the membrane effective fixed charges and also the free salt content in the membrane. They reported that solvation energy for monovalent ions was low, whereas their permeation and partition to the membrane are little dependent on the limitation to fixed charges. Geise et al. [33] speculated that the effective size of an ion diffusing through a polymer likely ranged between two extreme limits: a) the upper limit may be thought of as being the size of the fully hydrated ion (i.e., the extent of hydration observed when the ion is present in dilute aqueous solution), and b) the lower size limit in the case where the ion sheds its water of hydration, upon being transported into the polymer matrix, in favor of interactions with the polymer matrix. The hydration degree of an ion while transported in a polymeric membrane may be different from that observed in a dilute solution of this ion. When the salt concentration increased, the hydration number often decreased for several ions [34]. 
Figure 5 shows the membrane permeance values towards each ion as a function of the initial dominant salt concentrations. Assuming that the dependence of membrane permeances towards ions for both dominant and trace salt follow a similar trend as those shown for the dominant salt, as a preliminary approach $\operatorname{Eq}(7)$ was proposed to fit the dependence of membrane permeance toward each ion on the $\mathrm{NaCl}$ concentration. The predicted values (as trend lines) for $\mathrm{Cl}^{-}, \mathrm{Na}^{+}, \mathrm{NO}_{3}{ }^{-}$and $\mathrm{NH}_{4}{ }^{+}$are also shown in Figure 5 and the fitted parameters $\left(\mathrm{a}_{1}, \mathrm{a}_{2}, \mathrm{a}_{3}\right)$ are collected in Table 6 .

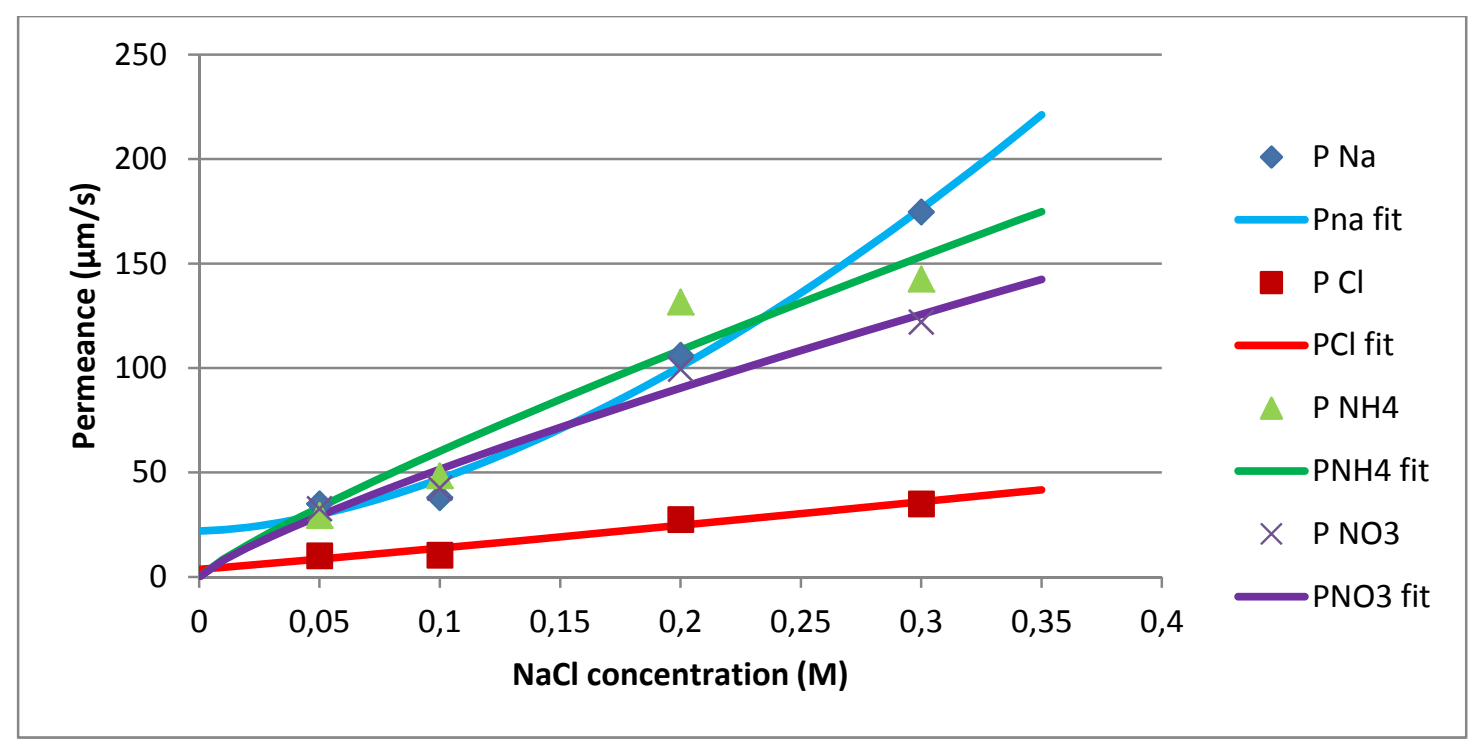

Figure 5. Membrane permeance values with respect to each ion as function of the feed $\mathrm{NaCl}$ concentration.

For the ions of the dominant salt $\left(\mathrm{Na}^{+}, \mathrm{Cl}^{-}\right)$the addition of the free term $\mathrm{a}_{3}$ was suitable for addressing the permeance trend in the low concentration range evaluated. However, for the trace ions the best fittings were obtained by taking the term $\mathrm{a}_{3}=0$.

\begin{tabular}{|c|c|}
\hline Ion & Correlation \\
\hline $\mathrm{Na}^{+}$ & $\mathrm{P}_{\mathrm{Na}+}=1138.4 \cdot \mathrm{C}_{\mathrm{NaCl}}{ }^{1.66}+22.0$ \\
\hline $\mathrm{Cl}^{-}$ & $\mathrm{P}_{\mathrm{Cl}-}=115.4 \cdot \mathrm{C}_{\mathrm{NaCl}}{ }^{1.06}+3.6$ \\
\hline $\mathrm{NH}_{4}^{+}$ & $\mathrm{P}_{\mathrm{NH} 4+}=427.7 \cdot \mathrm{C}_{\mathrm{NaCl}}{ }^{0.85}$ \\
\hline $\mathrm{NO}_{3}{ }^{-}$ & $\mathrm{P}_{\mathrm{NO} 3-}=334.2 \cdot \mathrm{C}_{\mathrm{NaCl}}{ }^{0.81}$ \\
\hline
\end{tabular}

Table 6. Correlation between membrane permeance to each ion and feed dominant salt concentration. 
It is worth pointing out that, at negative fixed charge, the Donnan rejection mechanism was expected to produce a decrease in the membrane permeance to $\mathrm{Na}^{+}$with increasing $\mathrm{NaCl}$ concentration, whereas the opposite trend was seen in our results. This fact indicated that the actual rejection mechanism is complex and is not limited to a combination of Donnan exclusion and steric hindrance. It is also worth stressing that due to the action of spontaneously-arising electric field the ion rejection was not directly correlated with the membrane permeance and strongly depended on the direction of movement of this ion by that field.

As seen from Figure 5, membrane permeance towards the cation of the dominant salt $\left(\mathrm{Na}^{+}\right)$was higher than that towards the anion of the dominant salt $\left(\mathrm{Cl}^{-}\right)$, giving rise to a positive electric field across the membrane. Figure 6 shows the behavior of trace ions due to this electric field.

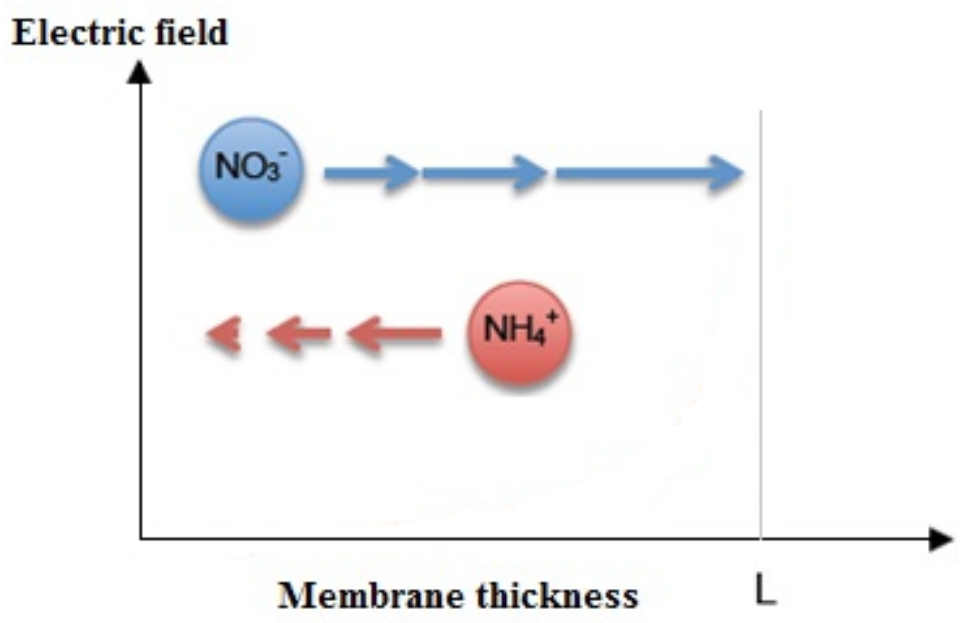

Figure 6. Scheme of the electric field arisen in the membrane

$\mathrm{NO}_{3}{ }^{-}$ions were strongly driven by the electric field trough the membrane towards the permeate (resulting in low and even negative rejections at low trans-membrane fluxes) while, conversely, just because of the opposite direction of electro-migration, $\mathrm{NH}_{4}{ }^{+}$ions presented a retardation, which produced strong rejections despite the high permeance to this ion.. 


\section{Conclusions}

In order to study the effect of dominant salt concentration on the removal of trace ions $\left(\mathrm{NH}_{4}{ }^{+}\right.$and $\left.\mathrm{NO}_{3}{ }^{-}\right)$, a set of $\mathrm{NF}$ experiments was designed with various $\mathrm{NaCl}$ concentrations and using $\mathrm{NH}_{4}{ }^{+}$and $\mathrm{NO}_{3}{ }^{-}$as trace ions. It was observed that higher dominant salt concentration led to lower removals of both the dominant salt itself and trace ions.

The applicability of SDEFM was confirmed, since it was possible to fit the experimental data by means of the model, even in the case of negative rejections, such as those of $\mathrm{NO}_{3}{ }^{-}$ion. The successful SDEFM fitting highlighted the importance of polarization layer and electric-field effects on which the model is based.

It was proven that the dominant salt has an important impact on the rejection of trace ions, not only for its concentration effects, but also via the different values of membrane permeance with respect to the dominant salt ions $\left(\mathrm{Na}^{+}\right.$and $\left.\mathrm{Cl}^{-}\right)$. It was found that the membrane permeance to $\mathrm{Na}^{+}$ion was higher than to $\mathrm{Cl}^{-}$ion, which gave rise to an electric field that caused negative rejections of the trace anion, $\mathrm{NO}_{3}{ }^{-}$, since this was strongly accelerated by that electric field. At the same time, the rejection of the trace cation, $\mathrm{NH}_{4}^{+}$, was much higher, because it was retarded by the same electric field.

The dependences of membrane permeance towards salt and ions on the dominant-salt concentration could be approximated by three-parameter empirical relationships.

\section{Acknowledgments}

This research was supported by the ZERO-DISCHARGE project (CTQ2011-26799) and Waste2Product project (CTM2014-57302-R) financed by the Ministerio de Economía y Competitividad (MINECO) and the Catalan Government (Project Ref. 2014SGR50), Spain. The work of Mònica Reig was supported by the Spanish Ministry (MINECO) within the scope of the grant BES-2012-051914.

We want to thank the contribution of Dow Chemical for the supply of the membranes and we would also like to acknowledge to M. Herrera for his contribution to the project. 


\section{References}

[1] M. Su, D.-X. Wang, X.-L. Wang, M. Ando, T. Shintani, Rejection of ions by NF membranes for binary electrolyte solutions of $\mathrm{NaCl}, \mathrm{NaNO} 3, \mathrm{CaCl} 2$ and $\mathrm{Ca}(\mathrm{NO} 3) 2$, Desalination. 191 (2006) 303308.

[2] K.L. Tu, L.D. Nghiem, A.R. Chivas, Coupling effects of feed solution $\mathrm{pH}$ and ionic strength on the rejection of boron by NF/RO membranes, Chem. Eng. J. 168 (2011) 700-706.

[3] R. Epsztein, O. Nir, O. Lahav, M. Green, Selective nitrate removal from groundwater using a hybrid nanofiltration-reverse osmosis filtration scheme, Chem. Eng. J. 279 (2015) 372-378.

[4] M. Pontié, H. Dach, J. Leparc, M. Hafsi, A. Lhassani, Novel approach combining physico-chemical characterizations and mass transfer modelling of nanofiltration and low pressure reverse osmosis membranes for brackish water desalination intensification, Desalination. 221 (2008) 174-191.

[5] A. Efligenir, S. Déon, P. Fievet, C. Druart, N. Morin-Crini, G. Crini, Decontamination of polluted discharge waters from surface treatment industries by pressure-driven membranes: Removal performances and environmental impact, Chem. Eng. J. 258 (2014) 309-319.

[6] L. Paugam, S. Taha, G. Dorange, P. Jaouen, F. Quéméneur, Mechanism of nitrate ions transfer in nanofiltration depending on pressure, $\mathrm{pH}$, concentration and medium composition, J. Memb. Sci. 231 (2004) 37-46.

[7] J. Wang, D.S. Dlamini, A.K. Mishra, M.T.M. Pendergast, M.C.Y. Wong, B.B. Mamba, et al., A critical review of transport through osmotic membranes, J. Memb. Sci. 454 (2014) 516-537.

[8] X. Wang, B. Li, T. Zhang, X. Li, Performance of nanofiltration membrane in rejecting trace organic compounds: Experiment and model prediction, Desalination. 370 (2015) 7-16.

[9] K. Thibault, H. Zhu, A. Szymczyk, G. Li, The averaged potential gradient approach to model the rejection of electrolyte solutions using nanofiltration: Model development and assessment for highly concentrated feed solutions, Sep. Purif. Technol. 153 (2015) 126-137.

[10] S. Déon, A. Escoda, P. Fievet, P. Dutournié, P. Bourseau, How to use a multi-ionic transport model 
to fully predict rejection of mineral salts by nanofiltration membranes, Chem. Eng. J. 189-190 (2012) 24-31.

[11] Y. Roy, M.H. Sharqawy, J.H. Lienhard, Modeling of flat-sheet and spiral-wound nanofiltration configurations and its application in seawater nanofiltration, J. Memb. Sci. 493 (2015) 360-372.

[12] A.M.F. Shaaban, A.I. Hafez, M.A. Abdel-Fatah, N.M. Abdel-Monem, M.H. Mahmoud, Process engineering optimization of nanofiltration unit for the treatment of textile plant effluent in view of solution diffusion model, Egypt. J. Pet. (2016).

[13] Z.V.P. Murthy, L.B. Chaudhari, Separation of binary heavy metals from aqueous solutions by nanofiltration and characterization of the membrane using Spiegler-Kedem model, Chem. Eng. J. 150 (2009) 181-187.

[14] D. Paul, Reformulation of the solution-diffusion theory of reverse osmosis, J. Memb. Sci. 241 (2004) 371-386.

[15] S. Bason, Y. Kaufman, V. Freger, Analysis of ion transport in nanofiltration using phenomenological coefficients and structural characteristics, J. Phys. Chem. B. 114 (2010) 3510-3517.

[16] A. Yaroshchuk, X. Martínez-Lladó, L. Llenas, M. Rovira, J. de Pablo, Solution-diffusion-film model for the description of pressure-driven trans-membrane transfer of electrolyte mixtures: One dominant salt and trace ions, J. Memb. Sci. 368 (2011) 192-201.

[17] A. Yaroshchuk, X. Martínez-Lladó, L. Llenas, M. Rovira, J. de Pablo, J. Flores, et al., Mechanisms of transfer of ionic solutes through composite polymer nano-filtration membranes in view of their high sulfate/chloride selectivities, Desalin. Water Treat. 6 (2009) 48-53.

[18] A. Yaroshchuk, M.L. Bruening, E.E. Licón Bernal, Solution-Diffusion-Electro-Migration model and its uses for analysis of nanofiltration, pressure-retarded osmosis and forward osmosis in multi-ionic solutions, J. Memb. Sci. 447 (2013) 463-476.

[19] N. Fridman-Bishop, O. Nir, O. Lahav, V. Freger, Predicting the Rejection of Major Seawater lons by Spiral-Wound Nanofiltration Membranes, Environ. Sci. Technol. 49 (2015) 8631-8638.

[20] R. Abu-Rjal, V. Chinaryan, M.Z. Bazant, I. Rubinstein, B. Zaltzman, Effect of concentration polarization on permselectivity, Phys. Rev. E. (2014) 012302.1-012302.10. 
[21] N. Pages, A. Yaroshchuk, O. Gibert, J.L. Cortina, Rejection of trace ionic solutes in nanofiltration: Influence of aqueous phase composition, Chem. Eng. Sci. 104 (2013) 1107-1115.

[22] M. Reig, N. Pagès, E. Licon, C. Valderrama, O. Gibert, A. Yaroshchuk, et al., Evolution of electrolyte mixtures rejection behaviour using nanofiltration membranes under spiral wound and flat-sheet configurations, Desalin. Water Treat. In press (2014).

[23] C.C. Wamser, M.I. Gilbert, Detection of surface functional group asymmetry in interfaciallypolymerized films by contact angle titrations, Langmuir. 8 (1992) 1608-1614.

[24] S.H. Kim, S.-Y. Kwak, T. Suzuki, Positron annihilation spectroscopic evidence to demonstrate the flux-enhancement mechanism in morphology-controlled thin-film-composite (TFC) membrane., Environ. Sci. Technol. 39 (2005) 1764-70.

[25] A.E. Childress, M. Elimelech, Relating Nanofiltration Membrane Performance to Membrane Charge (Electrokinetic) Characteristics, Environ. Sci. Technol. 34 (2000) 3710-3716.

[26] V. Freger, S. Srebnik, Mathematical model of charge and density distributions in interfacial polymerization of thin films, J. Appl. Polym. Sci. 88 (2003) 1162-1169.

[27] G.M. Geise, D.R. Paul, B.D. Freeman, Fundamental water and salt transport properties of polymeric materials, Prog. Polym. Sci. 39 (2014) 1-42.

[28] N. Hilal, H. Al-Zoubi, A.W. Mohammad, N.A. Darwish, Nanofiltration of highly concentrated salt solutions up to seawater salinity, Desalination. 184 (2005) 315-326.

[29] J.M. Skluzacek, M.I. Tejedor, M.A. Anderson, NaCl rejection by an inorganic nanofiltration membrane in relation to its central pore potential, J. Memb. Sci. 289 (2007) 32-39.

[30] A.E. Yaroshchuk, Rejection of single salts versus transmembrane volume flow in RO/NF: thermodynamic properties, model of constant coefficients, and its modification, J. Memb. Sci. 198 (2002) 285-297.

[31] A.E. Yaroshchuk, V. Ribitsch, The uses of non-steady-state membrane characterisation techniques for the study of transport properties of active layers of nanofiltration membranes: theory with experimental examples, Chem. Eng. J. 80 (2000) 203-214. 
[32] S. Bason, O. Kedem, V. Freger, Determination of concentration-dependent transport coefficients in nanofiltration: Experimental evaluation of coefficients, J. Memb. Sci. 326 (2009) 197-204.

[33] G.M. Geise, B.D. Freeman, D.R. Paul, Characterization of a sulfonated pentablock copolymer for desalination applications, Polymer (Guildf). 51 (2010) 5815-5822.

[34] V.N. Afanas'ev, Solvation of electrolytes and nonelectrolytes in aqueous solutions., J. Phys. Chem. B. 115 (2011) 6541-63. 